Corrigendum

\title{
Corrigendum to "Behaviour of the Foramen Ovale Flow in Fetuses with Intrauterine Growth Restriction"
}

\author{
Ângela R. L. Nader, ${ }^{1}$ Paulo Zielinsky (D), ${ }^{1,2}$ Alexandre Antonio Naujorks, ${ }^{1}$ \\ Luiz Henrique S. Nicoloso, ${ }^{1}$ Antonio Luiz Piccoli Junior, ${ }^{1}$ Natássia Miranda Sulis, ${ }^{1}$ \\ Luiza Ferreira van der Sand, ${ }^{1}$ Victoria de Bittencourt Antunes, ${ }^{1}$ \\ Gabriela dos Santos Marinho, ${ }^{1}$ Fernanda Greinert dos Santos, ${ }^{1}$ Natan Pereira Gosmann, ${ }^{3}$ \\ Eduardo Becker Júnior, ${ }^{1}$ Renato Frajndlich, ${ }^{1}$ Tamara Beherens, ${ }^{1}$ \\ Marcelo Brandão da Silva, ${ }^{1}$ Carolina Barbisan, ${ }^{1}$ Stefano Busato, ${ }^{1}$ Mauro Lopes, ${ }^{1}$ \\ and Caroline Klein ${ }^{1}$
}

${ }^{1}$ Unidade de Cardiologia Fetal, Instituto de Cardiologia do Rio Grande do Sul, Porto Alegre, RS, Brazil

${ }^{2}$ Departmento de Pediatria, Universidade Federal do Rio Grande do Sul (UFRGS), Porto Alegre, RS, Brazil

${ }^{3}$ Hospital de Clinicas de Porto Alegre, Porto Alegre, RS, Brazil

Correspondence should be addressed to Paulo Zielinsky; zielinsky@cardiol.br

Received 8 March 2018; Accepted 11 March 2018; Published 22 July 2018

Copyright (c) 2018 Ângela R. L. Nader et al. This is an open access article distributed under the Creative Commons Attribution License, which permits unrestricted use, distribution, and reproduction in any medium, provided the original work is properly cited.

In the article titled "Behaviour of the Foramen Ovale Flow in Fetuses with Intrauterine Growth Restriction" [1], the name of sixteenth author was given incorrectly as Caroline Barbisan. The author's name should have been written as Carolina Barbisan. The revised authors' list is shown above.

\section{References}

[1] Â. R. L. Nader, P. Zielinsky, A. A. Naujorks et al., "Behaviour of the foramen ovale flow in fetuses with intrauterine growth restriction," Obstetrics and Gynecology International, vol. 2018, Article ID 1496903, 6 pages, 2018. 


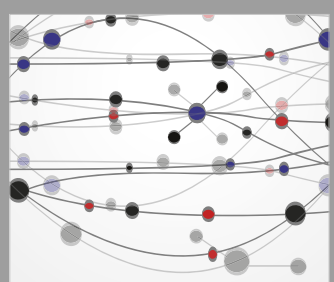

The Scientific World Journal
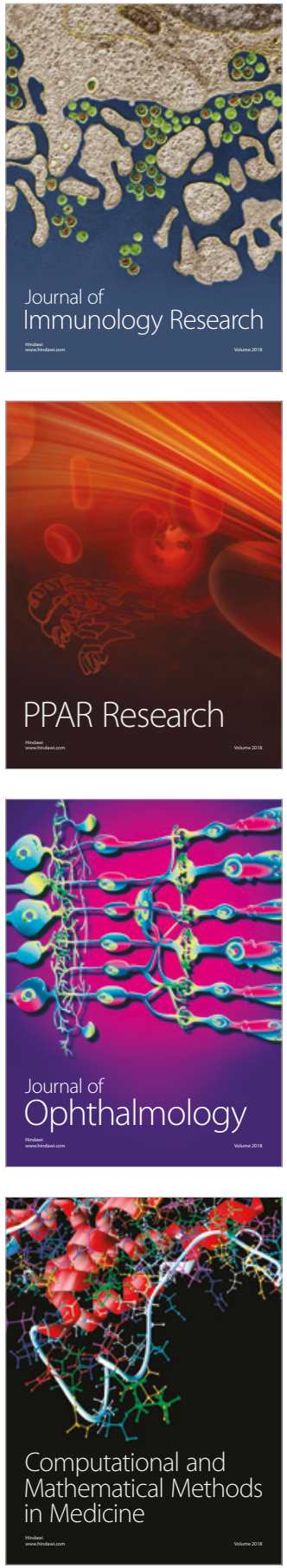

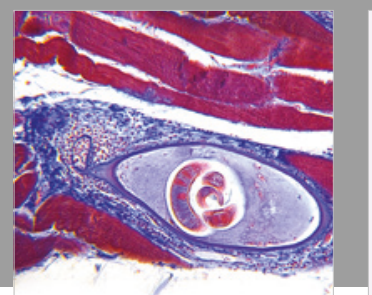

Gastroenterology Research and Practice

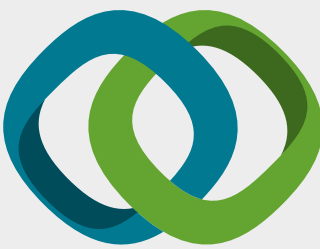

\section{Hindawi}

Submit your manuscripts at

www.hindawi.com
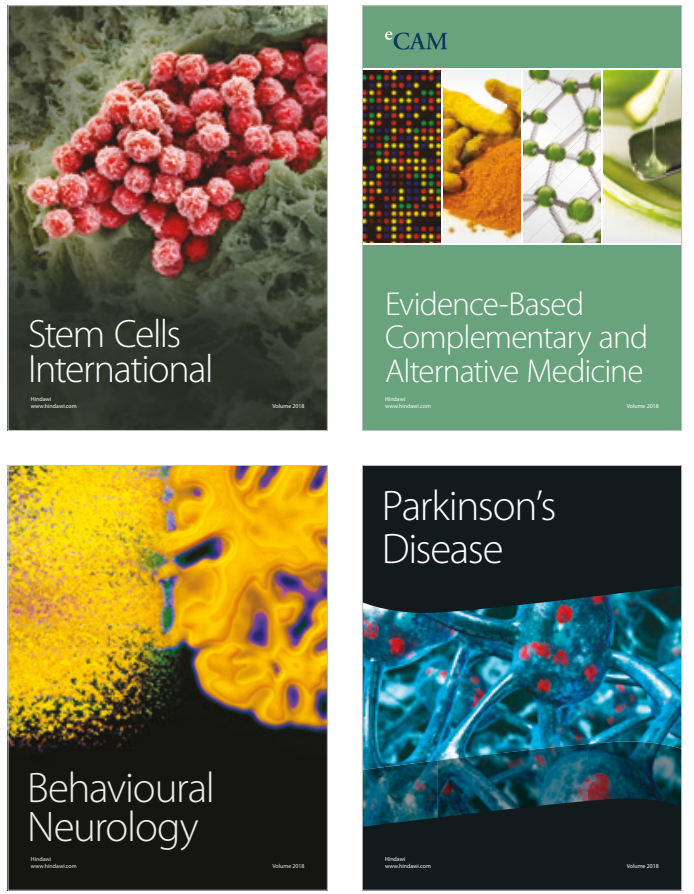

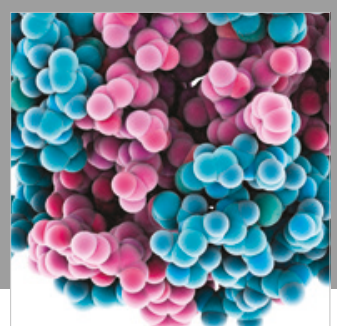

ournal of

Diabetes Research

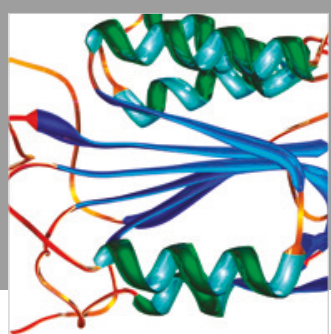

Disease Markers
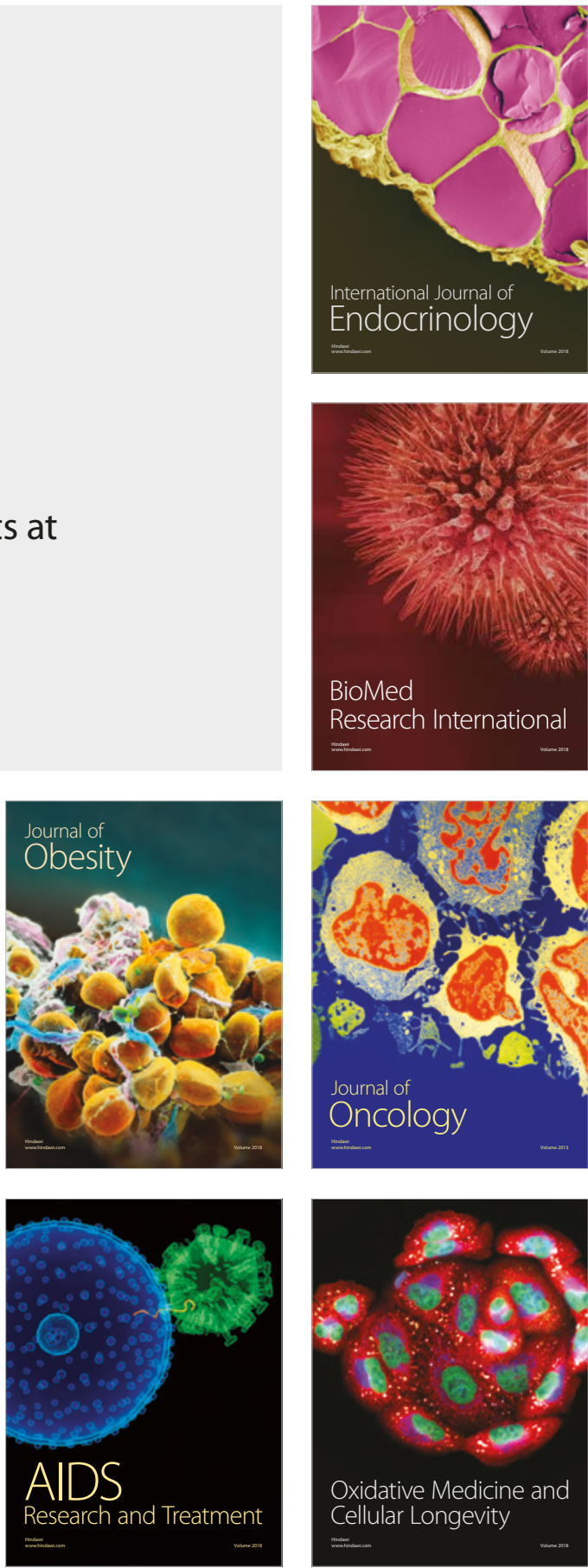